\title{
Giant triple coronary artery aneurysms from incomplete Kawasaki disease
}

\author{
Ranjan K Shetty, ${ }^{1}$ Vivek G Raman, ${ }^{1}$ Saarwaani Vallabhajosyula, ${ }^{2}$ \\ Saraschandra Vallabhajosyula ${ }^{3}$
}

\section{${ }^{1}$ Division of Cardiovascular Medicine, Department of Medicine, Kasturba Medical College, Manipal University, Manipal, Karnataka, India ${ }^{2}$ Kasturba Medical College, Manipal University, Manipal Karnataka, India \\ ${ }^{3}$ Department of Internal Medicine, Creighton University School of Medicine, Omaha, Nebraska, USA \\ Correspondence to \\ Dr Saraschandra \\ Vallabhajosyula, \\ SaraschandraVallabhajosyula1 @creighton.edu}

Accepted 19 March 2015

CrossMark
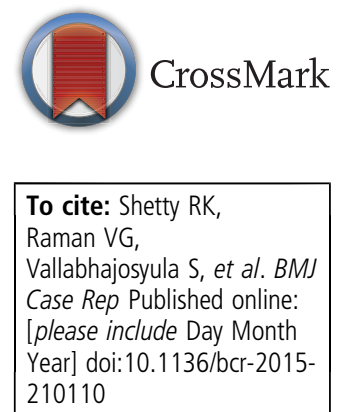

\section{DESCRIPTION}

A 23-year-old woman presented with a new-onset 7/10 substernal, non-radiating chest heaviness of 1-day duration. She did not report any familial cardiac disease or sick contacts. Vital signs and cardiovascular examinations were unremarkable. Laboratory parameters revealed borderline troponin-T elevation. ECG demonstrated $3 \mathrm{~mm}$ flat ST-segment depressions with T-wave inversions in $\mathrm{V}_{1}-\mathrm{V}_{4}$ and transthoracic echocardiogram demonstrated left ventricular ejection fraction of $40-45 \%$ with inferolateral hypokinesis. Emergent coronary angiogram revealed severe aneurysmal dilation of left main, proximal left anterior descending, left circumflex and proximal right coronary arteries with poor distal run-off (figures 1-3). A diagnosis of Kawasaki disease (KD) was suspected; however, retrospective questioning yielded no fever or history of lymphadenopathy. The patient was medically optimised on aspirin, statins, clopidogrel, nicorandil and isosorbide dinitrate. In view of triple vessel involvement (including left main), surgical intervention was offered. The patient was unable to afford surgery and was subsequently lost to follow-up.

Coronary artery aneurysms (CAA) are usually a consequence of atherosclerotic cardiovascular disease (ASCVD) and are noted during 0.15-4.9\% of angiographic series. ${ }^{1}{ }^{2} \mathrm{KD}$, which is an acute self-limiting vasculitis affecting the tunica media, should be suspected in patients without ASCVD risk factors, and has high mortality. ${ }^{1-3}$ Clinically, patients manifest with ventricular hypokinesis/akinesis due to multiple myocardial infarctions and/or myocarditis. ${ }^{2}$ Angiography may demonstrate CAA,

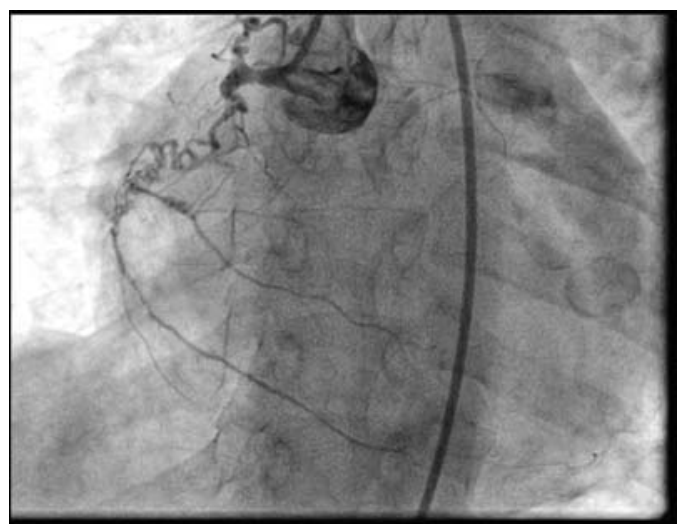

Figure 1 Left anterior oblique cranial view demonstrating aneurysmal proximal right coronary artery with poor distal run-off.

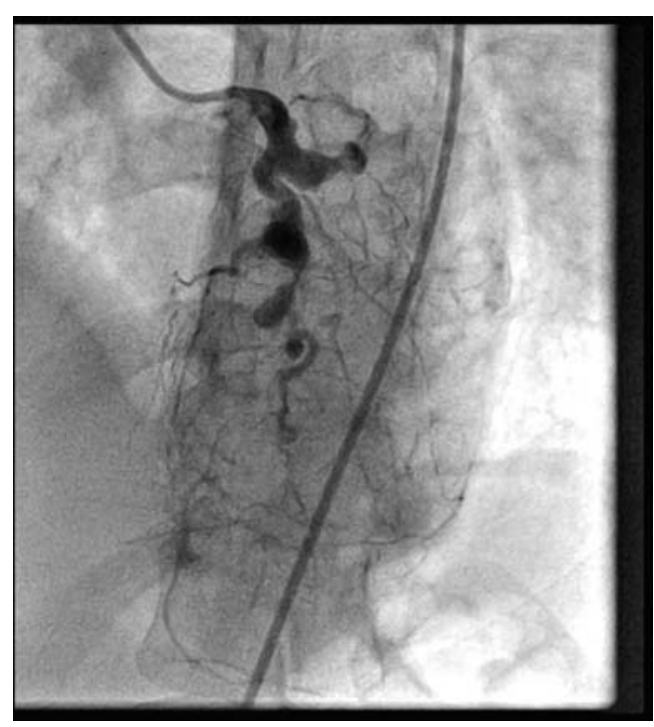

Figure 2 Anteroposterior cranial view demonstrating aneurysmal dilation of left main, left anterior descending and left circumflex arteries.

ectasia, calcifications, increased collaterals and thrombosis. ${ }^{2}{ }^{3}$ There is lack of adequate evidence on the management (grade C). ${ }^{13}$ Antiplatelet and anticoagulant drugs are the mainstay of therapy to prevent thrombosis with subsequent surgical intervention depending on the complexity of the lesions. ${ }^{1}$

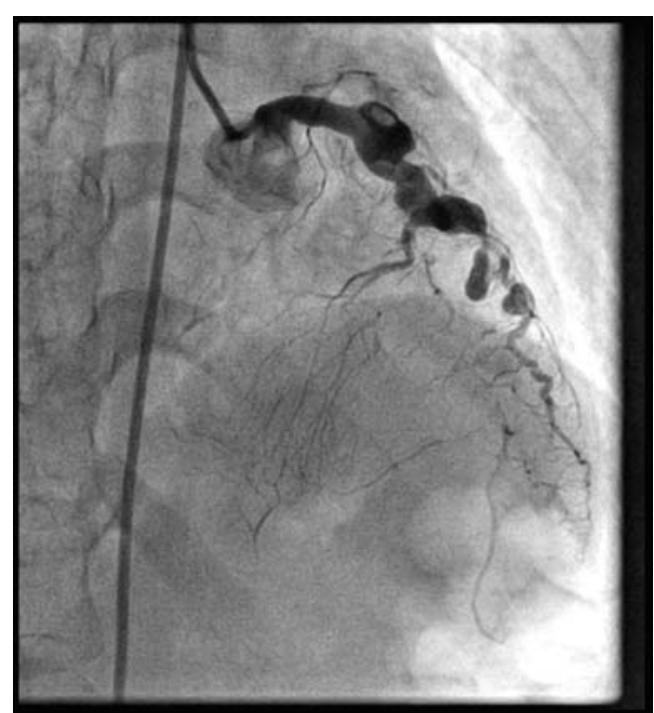

Figure 3 Right anterior oblique cranial view demonstrating dilated and beaded appearance of left anterior descending artery. 


\section{Learning points}

- The report highlights a common manifestation of Kawasaki disease (KD) presenting without a prodromal illness.

- Also highlighted is the rare involvement of all three coronary arteries in the form of giant coronary artery aneurysms (CAA).

- We briefly elucidate on the presentation, diagnosis and management of CAA in KD with a focus on the need for further literature.

Contributors RKS, VGR were involved in evaluation of the patient, critical evaluation and finalising of the manuscript; Saarwaani Vallabhajosyula was involved in evaluation of the patient, drafting of the manuscript, literature review; Saraschandra Vallabhajosyula was involved in literature review, drafting and finalising of the manuscript, correspondence with the journal.

Competing interests None.

Patient consent Obtained.

Provenance and peer review Not commissioned; externally peer reviewed.

\section{REFERENCES}

1 Bajaj R, Mamidala S, Bajaj $P$, et al. Non-atherosclerotic multiple coronary artery aneurysms. BMJ Case Rep 2013;2013:pii: bcr2013200553.

2 Jesuraj $M L$, Mukerjee $D$, Jesuraj $A V$, et al. Coronary artery ectasia in a patient with myocardial infarction. Cardiovasc J Afr 2011;22:36-7.

3 Neuburger JW, Takahashi M, Gerber MA, et al. Diagnosis, treatment, and long-term management of Kawasaki disease: a statement for health professionals from the Committee on Rheumatic Fever, Endocarditis, and Kawasaki Disease, Council on Cardiovascular Disease in the Young, American Heart Association. Pediatrics 2004;114:1708-33.

Copyright 2015 BMJ Publishing Group. All rights reserved. For permission to reuse any of this content visit http://group.bmj.com/group/rights-licensing/permissions.

BMJ Case Report Fellows may re-use this article for personal use and teaching without any further permission.

Become a Fellow of BMJ Case Reports today and you can:

- Submit as many cases as you like

- Enjoy fast sympathetic peer review and rapid publication of accepted articles

- Access all the published articles

- Re-use any of the published material for personal use and teaching without further permission

For information on Institutional Fellowships contact consortiasales@bmjgroup.com

Visit casereports.bmj.com for more articles like this and to become a Fellow 